\title{
HISTORY OF TECHNOLOGY AS AN AID TO PROBLEM SOLVING
}

\author{
Alan L. Prasuhn \\ Professor of Civil Engineering \\ South Dakota State University
}

\section{INTRODUCTION}

Motivation for this paper stems jointly from an extensive period of service on the ASCE Committee on History and Heritage of American Civil Engineering and the organizing and teaching of a course on the History of Technology. While on this committee, and most other engineering societies have a similar committee, I have served with a group of civil engineers all eminently respected in their respective areas of technical competence who have a common interest in the history and heritage of their profession. One of the goals of this committee is to create an awareness of the heritage of the engineering profession, and even more importantly, the significance of that heritage! One of the recognized ways to achieve this goal is by introducing into the engineering curriculum a course on the History of Engineering, the History of Technology, or even a course on "Technology and Society". The first two of the aforementioned courses are generally more scholarly than the third. Which type of course is offered by a particular school depends on a number of factors. My comments here, however, are appropriate to any of these courses.

I would like to first justify the need for such a course and then follow up with some of the unique opportunities available to the instructor. Stanley B. Hamilton, in a paper read before the Newcomen Society, listed six reasons engineers should study history (2):

1. The detective interest of tracing knowledge to its source.

2. The opportunity of sharing a disinterested companionship with others who are following kindred lines, as a member of such a body as our Society.

3. The broadening of interest in engineering from the purely technical to a humane and liberal field of study.

4. The light which the study of invention and discovery can throw on the working of the human mind.

5. The genuinely recreative form of relaxation which history provides.

6. The contribution which the History of Technology can make to the understanding of history in general. 
Neal FitzSimons, Chairman of the ASCE committee recently presented a paper to a meeting of educators (1) in which he stressed the value of such studies and followed this with his own list of six reasons the engineer should learn more about his heritage. Again, quoting:

1. Professional responsibility. It is incumbent upon every professional to have the cultural depth of knowing the history of the profession.

2. To learn from the real world experiences of our professional predecessors.

3. History provides a strong link to the public.

4. Professional inspiration.

5. To give perspective to the contributions made by engineers all over the world.

6. To get involved with history is fun!

These same themes have been stated and restated through the years. There are those who feel that a professional education is not complete if the individual has not been exposed to the history of his profession. But professionalism aside, technical competence is augmented by an adequate dose of historical perspective. Sir Issac Newton, the English mathematician, scientist and philosopher, said that "If I have seen further, it is by standing on the shoulders of giants".

The foregoing represent the traditional arguments in favor of a History of Technology course. In the remainder of the paper, I would like to present other advantages of such a course and other worthwhile goals that an instructor can achieve - particularly with regard to problem solving. Bear in mind that the history of mankind has been a continuous series of problems and searches for their solutions, and our need for problem solving has probably never been greater than at present. A course in History of Technology is one way to approach problem solving.

\section{TYPES OF PROBLEMS}

The first case in point is the recognition of the need for technological improvement. Historically, this need has frequently not been recognized, even in what is after the fact, patently obvious. As an example, consider the horse hamess used for centuries shown in Fig. 1. This device connected the prime mover - the horse - with the object to be moved, be it a wagon, plow, or horse gin. It did the job - a certain amount of power could be developed and a task accomplished. Whereas it should have been taken to task, it was never questioned that it developed what certainly could be called a "small horse power". 


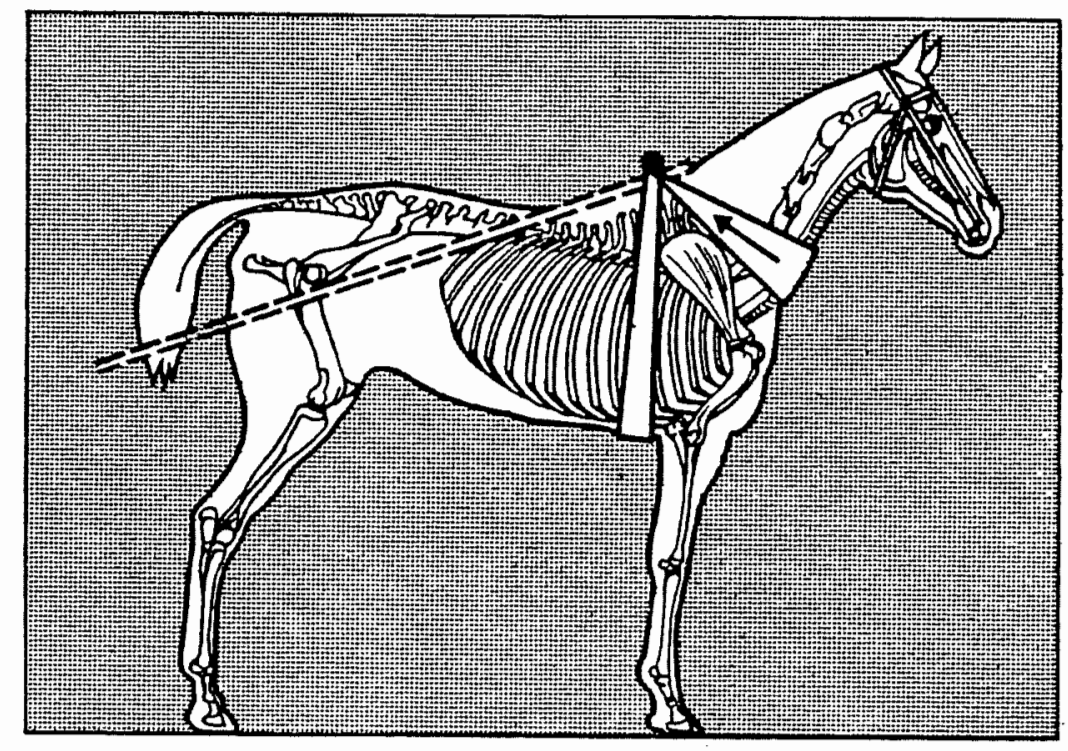

Fig. 1. Ancient harness pressing on animal!s windpipe.

Yet, what a simple change was required to develop̃ a "larger horse power"! As much as 300 to 400 percent more power in fact. The change, which evolved during the 10th century is shown in Fig. 2. The thrust was removed from the horse's neck and distributed over the horse's shoulders. A change from a cantilevered force to a direct application in the desired direction. The improvement, ignored for centuries, should be apparent to the poorest student of mechanics.

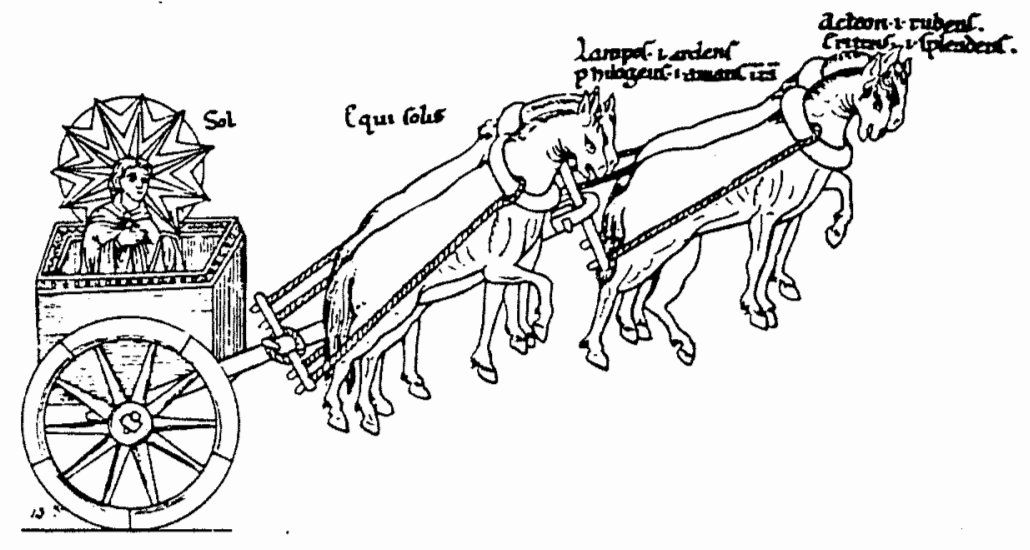

Fig. 2. Improved medieval harness.

The problem, then, is how do you create an awareness in the student so that he will recognize the existence of a problem when the problem itself hasn't been recognized, or has been accepted as the current practice? How 
does the instructor instill in the student the need to be creative - to hunt out the problem - to be dissatisfied with the status quo? This is a luxury that rarely can be covered in the traditional engineering courses. But, a history of technology course provides an ideal environment for such considerations. The student can first be exposed to historic examples such as the aforementioned hamess, and then challenged to consider an example either from everyday. Iife or from the field of engineering, and suggest first failings in the prevailing technology, and second an improvement.

A second example illustrating the same point is the elementary mechanics problem in Fig. 3. The twelfth century invention of the hinged stern rudder, with its increased mechanics advantage, made the maneuvering of a ship far easier.

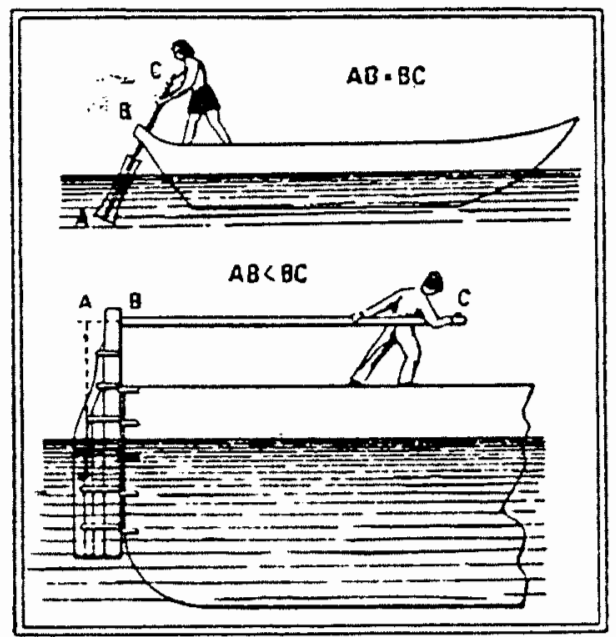

Fig. 3. Old and new rudders.

Another somewhat more recent example from the agricultural field illustrates another point relative to consideration of problems and solutions. In 1701 Jethro Tull invented the seed drill. In this case, the problem was recognized in advance and the advantages that would accrue to the user were readily apparent. Less labor would be required to place the seeds in the ground. Time would be saved. Rather than a much more random system, the seeds could be placed at the proper depth and spacing, ensuringmore reliable germination and better growth. In addition to these obvious benefits, the new seed drill lead to other improvements and inventions which were probably not contemplated in advance of the actual use of the seed drill. The first of these subsequent inventions soon became obvious as a result of the straight rows of crops which resulted from the planter. More mechanized work was now possible. In just a few years, Tull had designed and was using a horse-hoe (1714). An additional saving in time and labor resulted, accompanied by a further increase in yield. 
The lesson here is not as difficult to apply as that in the first type of problem. Nevertheless, it behooves the engineer to recognize the full potential from a new product or process. In our modern society, we see the examples all around us - from Tang to the laser. To stress this point, the student may be required to take a relatively new development and propose a new use, or take an historical example and suggest a second development that might have followed from it. The possibilities are endless ranging from the invention of gunpower which lead to attempted gunpower machines (Fig. 4), which proved a failure, to the discovery of the vacuum and consequently lift pumps or "atmospheric engines" (the first steam engines of Papin and Newcomen). The examples can be general or they can be restricted to a particular field of engineering or technology.

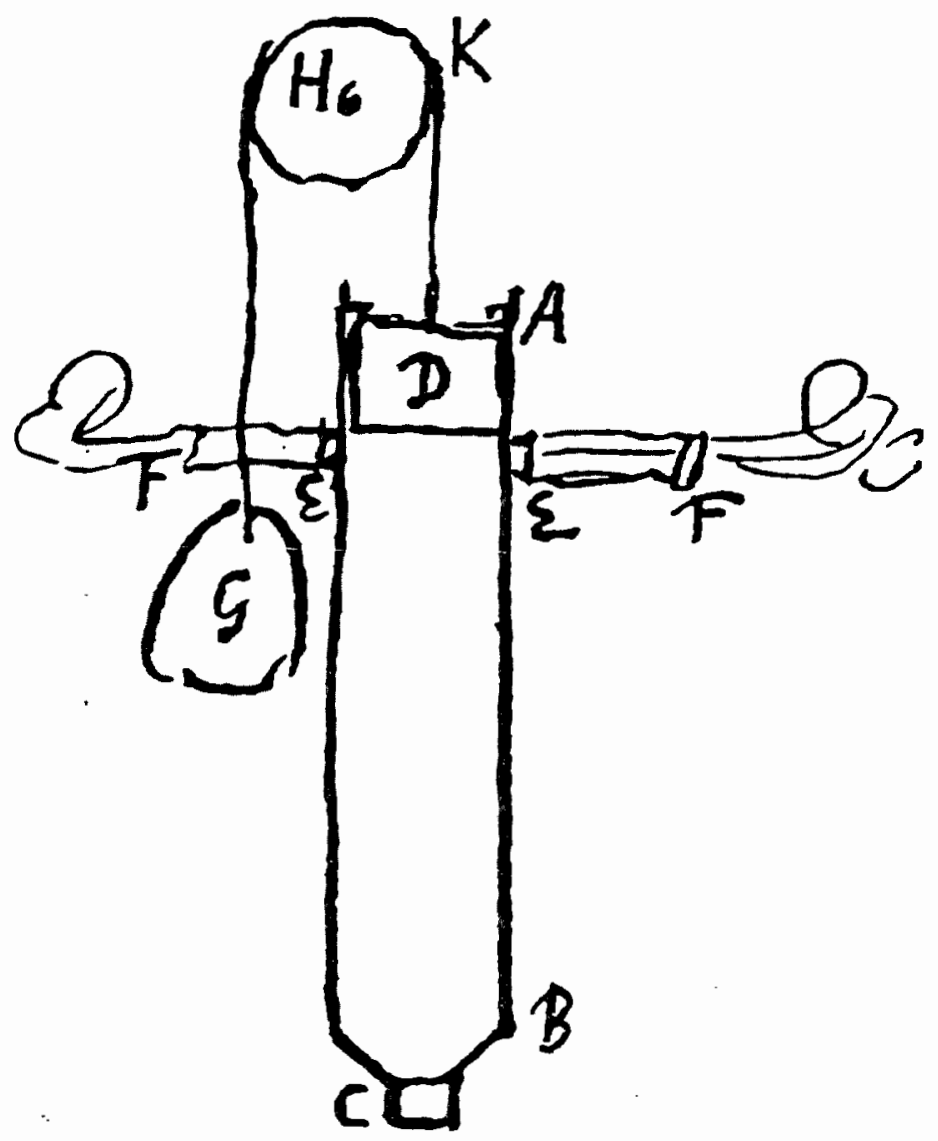

Fig. 4. Freehand sketch by Christian Huygens of gunpowder machine (1673) .

As another approach, a portion of the course can be presented on the so-called heroic scale by tracing the career of particularly significant individuals. This permits the student to examine positive as well as possibly negative traits in an individual's make-up and approach to problem solving. Take the case of Isambard Kingdom Brunel, the famous Victorian engineer. The same perseverance that enabled him to complete the world's 
first under-river tunnel, the Thames tunnel begun by his father Marc. Brunel, and giant ocean-going steam ships including the Great Eastern, also resulted in his stubbornness in refusing to give up the somewhat ill-conceived broad gauge for his Great Western Railroad, and his doomed-from-the-start atmospheric railway. In this latter example he stuck with the project in spite of ever increasing difficulties for several years before admitting defeat. One can consider these examples in either a favorable or unfavorable light. The fact remains, nonetheless, that here was an individual looking for solutions to problems that for one reason or another almost defied solution. In the case of the broad gauge, it was purely a question of being too late - the rest of the English railroads were standard gauge. The atmospheric railroad was defeated because of a whole brigade of technological difficulties: sealing the leather flap valve which ran the length of the air pipe, keeping rats from eating the leather valve, designing grade crossings, and switching problems, to mention just a few.

One can contrast Brunel and his approach to engineering and problem solving, with the career of a slightly earlier Scottish engineer, Thomas Telford. The string of world famous roads, bridges, aqueducts, and canals built by Telford, and remaining today mark him as an engineering genius perhaps without equal. In recognition of his efforts he was elected the first president of the Institution of Civil Engineers. He provided reliable and often imaginative solutions to some of the most difficult problems of his day - for example, bridging the Menai Straits and improving transportation in the then nearly wild, and certainly poverty-stricken, Scottish Highlands.

In the case of both Brunel and Telford (and other potential examples as we11), much of the material can be presented to the students in terms of a problem (what solution would you propose?) followed by the classic solution. To illustrate, a safe all-weather crossing of the Menai Straits was desired to improve communications between London and Ireland. The British Admiralty required clearence for their tallest sailing vessels, even during construction. No bridge of this magnitude have ever been attempted, where do you start?

As a side benefit of the serious examination of a number of such individuals, other characteristics emerge that I believe have a message for our time. Many had an appreciation and even an active participation in the arts - as poets, skilled musicians, and at least acceptable artists; traits which we all too often supress or discourage in our engineering students.

The final class of problems is by far the most complex in its nature and probably the most perplexing to solve. Stated simply, how does the technology develop for a product or process $A$, when $A$ is dependent on a second parallel development $B$, which may in turn be dependent for its success on the satisfactory development of A? The student may be presented with the classical example of the steam engine. The discussion however, 
may be proceeded by another question 'What single event was most responsible for the start of the Industrial Revolution?" The date incidently is generally considered to fall into the time span of 1700-1750. The students will more than likely choose the development of the steam engine. We will return to this point in due course.

If we concentrate on just the progress in the conception and evolution of the steam engine the picture that emerges, in somewhat condensed form, is the following. The first item might be the sound theoretical sketches and reasoning by Denis Papin who conceived of a workable steam pump as early as 1690 (Fig. 5). Thomas Savery invented a steam pump in England in 1698, but it was unable to drain the mines for which it was intended, and was used only for small water supplies. Credit for the first successful large steam engine (again for mine drainage) must go to Thomas Newcomen for his "atmospheric" steam engine of 1712. Power was developed by the creation of a partial vacuum in the cylinder due to condensation of steam, the atmosphere then pushed down the cylinder. The enormous inefficiency (in its most improved state only about $1 \%$ ) was finally overcome by James Watt 64 years later in 1776 using a separate condenser. This eliminated the continual heating and cooling of the cylinder. The increased thermal efficiency reduced coal consumption three or four fold.

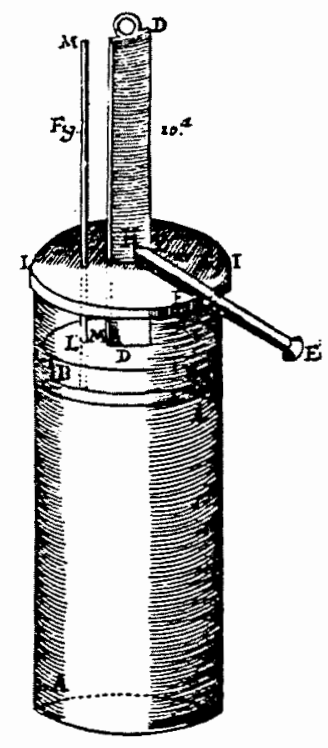

Fìg. 5. Papin's 1690 atmospheric steam engine.

The time required to develop a useable steam engine (from 1690 to 1712) was only 22 years. Why were 64 years required to make the first significant improvements? Improvements, in fact, which were required before the steam engine was suitable for any use except the draining of coal mines where adequate fuel was available. 
The answer lies not so much in the improved understanding of thermodynamics (which did occur during this period), but rather in other developments which took place during the interim. These developments, the importance of which can not be overestimated, includes the perfecting of the technique of smelting iron ore with coke in 1709 by Abraham Darby and the completion in 1774 of a boring mill by John Wilkinson. The first lead to the world's first large iron industry, so necessary for steam engines and milling machines alike. The second overcame the trickiest technological problem associated with the steam engine, the forming of a large constant diameter bore. To complete the circle, the steam engine was essential for providing the blast and other power requirements in the iron industry.

Let us return to the previous question concerning the industrial revolution. There are many who argue, to good effect, that the use of coke rather than charcoal in the wood-starved industrial area of England, provided the spark that ignited the industrial revolution which so altered the course of human history. That point can be debated. The students, or in fact the reader, might argue that the various steps are not of as equal an importance as implied here. Nevertheless, the point is made that there is a major combining of different technologies required for the successful completion of complex developments such as the steam engine. A valuable lesson may be learned here. Also in passing, and perhaps not insignificantly, it should be noted that Denis Papin, whose name started this discussion of the steam engine was an assistant to Christian Huygens, one of the leading experimenters with the unsuccessful gumpowder engine.

\section{CONCLUSIONS}

It is not intended that a course in the History of Technology be primarily a course in problem solving. In fact, this particular goal is never mentioned to the student, because I feel that the concept of problem solving should be a part of his subconscious rather than conscious education. As far as expressed course goals are concerned, the paper started with some twelve more-or-less independent goals or reasons to undertake such a course. The different types of problems presented here are introduced into the course during almost every class period. It creates a significant amount of class involvement, and I feel that the teaching of such a course on a problem-orientated basis has proven successful. It is granted that the approach is suitable for other courses as well, but it is a unique opportunity and to hark back to one of the original points: the History of Technology is fun - the concept of problem solving can be made fun too.

\section{ACKNOWLEDGEMENT}

Al1 figures are from Klemm, Friedrich, A History of Western Technology, The MIT Press, Cambridge, Mass., 1964, 401 pp., with permission of The MIT Press. 


\section{REFERENCES}

1. FitzSimons, N., "Heritage in the Civil Engineering Curriculum", Civil Engineering Education: Responding to the Challenges of Engineering Practice, Vo1. 1, ASCE, New York, 1979, pp. 603-607.

2. Hamilton, S. B., "Why Engineers Should Study History", The Newcomen Society, London, 1956. 